\title{
Synthesis, Characterization, and Evaluation of Boron-Doped Iron Oxides for the Photocatalytic Degradation of Atrazine under Visible Light
}

\author{
Shan Hu, Guanglong Liu, Duanwei Zhu, Chao Chen, and Shuijiao Liao \\ Laboratory of Plant Nutrition and Ecological Environment Research, Centre for Microelement Research of Huazhong Agricultural \\ University, Key Laboratory of Subtropical Agriculture and Environment, Ministry of Agriculture, Wuhan 430070, China \\ Correspondence should be addressed to Duanwei Zhu, zhudw@mail.hzau.edu.cn
}

Received 23 July 2011; Accepted 15 September 2011

Academic Editor: Shifu Chen

Copyright () 2012 Shan $\mathrm{Hu}$ et al. This is an open access article distributed under the Creative Commons Attribution License, which permits unrestricted use, distribution, and reproduction in any medium, provided the original work is properly cited.

Photocatalytic degradation of atrazine by boron-doped iron oxides under visible light irradiation was investigated. In this work, boron-doped goethite and hematite were successfully prepared by sol-gel method with trimethylborate as boron precursor. The powders were characterized by XRD, UV-vis diffuse reflectance spectra, and porosimetry analysis. The results showed that boron doping could influence the crystal structure, enlarge the BET surface area, improve light absorption ability, and narrow their band-gap energy. The photocatalytic activity of B-doped iron oxides was evaluated in the degradation of atrazine under the visible light irradiation, and B-doped iron oxides showed higher atrazine degradation rate than that of pristine iron oxides. Particularly, B-doped goethite exhibited better photocatalytic activity than B-doped hematite.

\section{Introduction}

Atrazine, 2-chloro-4-ethylamino-6-isopropylamino-1,3,5-triazine, has been widely used in the fields of corn, sorghum, orchard, and forest, controlling broad-leaf and grassy weeds [1]. However, due to the toxicity to aquatic organisms and mammals, high mobility, low-sorption affinity, and slow biodegradability [2, 3], atrazine has been banned by many European countries. It is frequently detected in ground water and surface water [4] and seriously influenced water quality. Therefore, many ways have been found to resolve atrazine contamination, such as advanced oxidation processes [5], microorganism removal [6], and microwave irradiation [7].

It has been reported that photocatalysis is effective way in the degradation of organic pollutants. $\mathrm{TiO}_{2}$ is considered to be the most promising photocatalyst due to its nontoxicity, chemical inertness, and high reactivity. Parra found that both suspended and supported $\mathrm{TiO}_{2}$ could destroy atrazine although atrazine could not be completely mineralized [8]. However, the widespread technological use of $\mathrm{TiO}_{2}$ is impaired by its wide-band gap $(3.2 \mathrm{eV})$, which can only be activated under UV light. Iron oxides especially goethite and hematite have been studied as photocatalysts in recent years because their lower band gap $(2.2 \mathrm{eV})$, and nonmental doping could improve reactivity of photocatalysts $[9,10]$. It is reported that $\mathrm{PE}$ films with boron-doped goethite has higher photo-induced degradation than pure PE films under the UV irradiation [11]. In this paper, B-doped goethite and hematite were prepared as photocatalysts, and enhancement of photocatalytic activity of atrazine degradation was observed under visible light irradiation.

\section{Experimental}

2.1. Materials. $\mathrm{Fe}\left(\mathrm{NO}_{3}\right)_{3},\left(\mathrm{CH}_{3} \mathrm{O}\right)_{3} \mathrm{~B}, \mathrm{KOH}$, methanol were supplied from Guoyao Chemical Co. (Shanghai, China) and atrazine was supplied from the Laboratories of Dr. Ehrenstorfer (Germany). All chemicals were used without further purification, and deionized water was used in all the experiments.

2.2. Preparation of Photocatalysts and Characterization. The original goethite (G-S-B0\%) was prepared according to the 


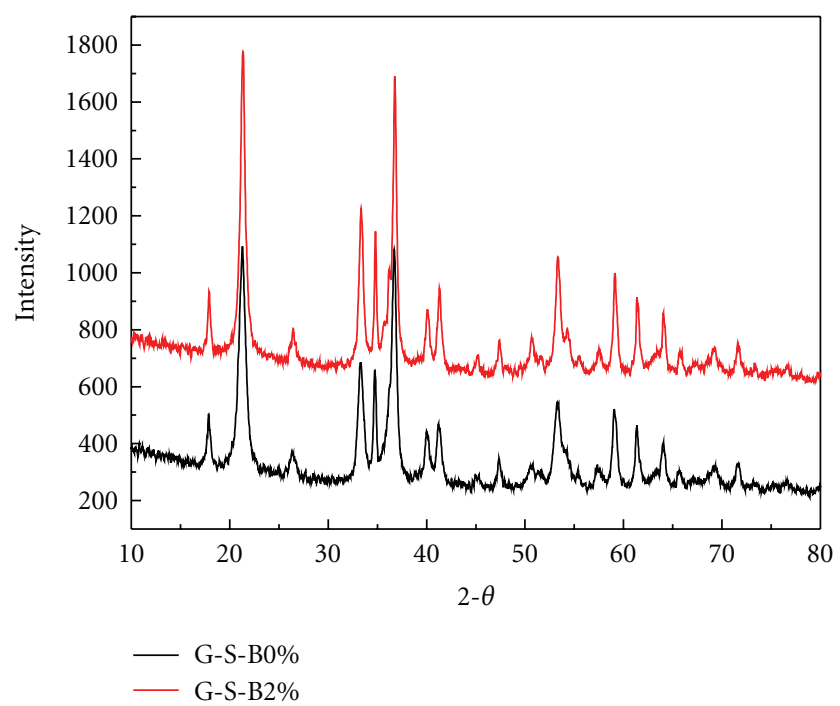

Figure 1: X-ray diffraction patterns of goethite and B-doped goethite.

method of Atkinson et al. [12], and the preparation of Bdoped goethite photocatalysts was the same as the method of Liao et al. [13], while the atomic weight ratio of $\mathrm{B}$ to Fe was 2\% (G-S-B2\%). Goethite and B-doped goethite were calcined at $400^{\circ} \mathrm{C}$ for $2 \mathrm{~h}$ to obtain the original hematite $(\mathrm{H}$ $\mathrm{S}-\mathrm{B} 0 \%)$ and B-doped hematite (H-S-B2\%), respectively.

The Brunauer-Emmett-Teller surface areas of the powder samples were determined by nitrogen adsorptiondesorption isotherm measurements on a ST-08 nitrogen adsorption apparatus. The X-ray powder diffraction pattern was obtained with a Brook D8 diffractometer using Fe K $\alpha$ radiation with an accelerating voltage of $40 \mathrm{kV}$ and current of $20 \mathrm{~mA}$. The UV-vis diffuse reflectance spectra of different iron oxides in the $190-900 \mathrm{~nm}$ were recorded using an American Lambda35 UV-vis spectrophotometer.

2.3. Photocatalytic Evaluation with Atrazine under Visible Light. The photocatalytic activities of pure and B-doped iron oxides nanoparticles were evaluated by the degradation of atrazine under visible light irradiation at a constant temperature $\left(25^{\circ} \mathrm{C}\right) .25 \mathrm{~mL} 10 \mathrm{mg} \cdot \mathrm{L}^{-1}$ atrazine solution was put in $50 \mathrm{~mL}$ of centrifugal test tube with $100 \mathrm{mg}$ different photocatalysts, and then all tubes were placed in a constant temperature shaking incubator at a speed of $190 \mathrm{r} \cdot \mathrm{min}^{-1}$. A $250 \mathrm{~W}$ metal halide lamp $(\lambda>385 \mathrm{~nm}$, JLZ250KN, Shanghai Yaming Co.) was put above all tubes as the visible light irradiation with a distance of $80 \mathrm{~cm}$. At different time intervals during the irradiation, samples were collected, filtered, and finally analyzed by HPLC (Agilent1100). Atrazine was detected at $222 \mathrm{~nm}$ and the mobile phase was methanol/water mixture $(80: 20, \mathrm{v} / \mathrm{v})$ at a flow rate of $1.0 \mathrm{~mL} \cdot \mathrm{min}^{-1}$ using C18 column $(4.6 \mathrm{~mm} \times 150 \mathrm{~mm})$.

\section{Results and Discussion}

3.1. Crystal Structure. XRD was carried out to investigate the changes of goethite and hematite phase structure after

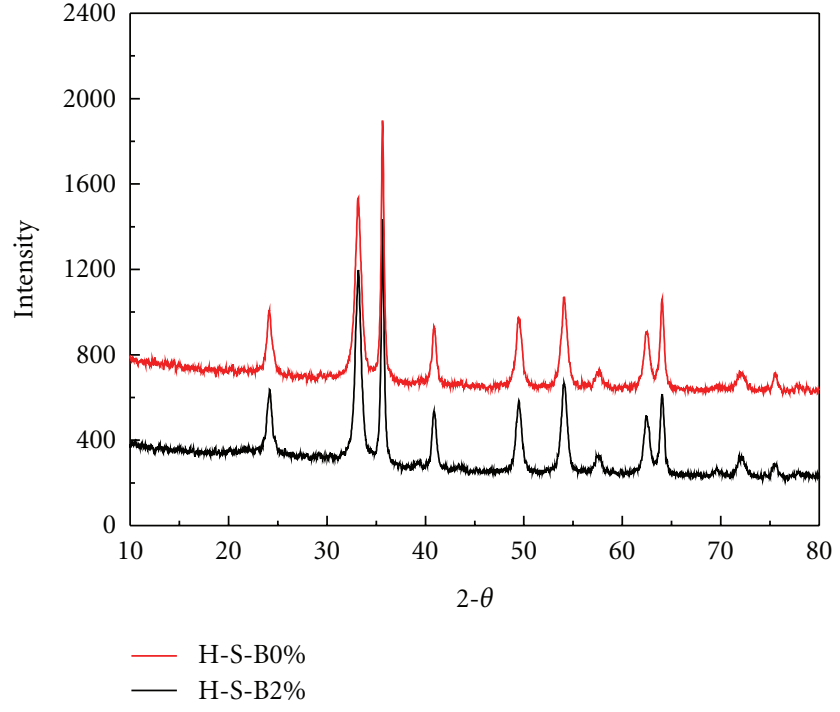

Figure 2: X-ray diffraction patterns of hematite and B-doped hematite.

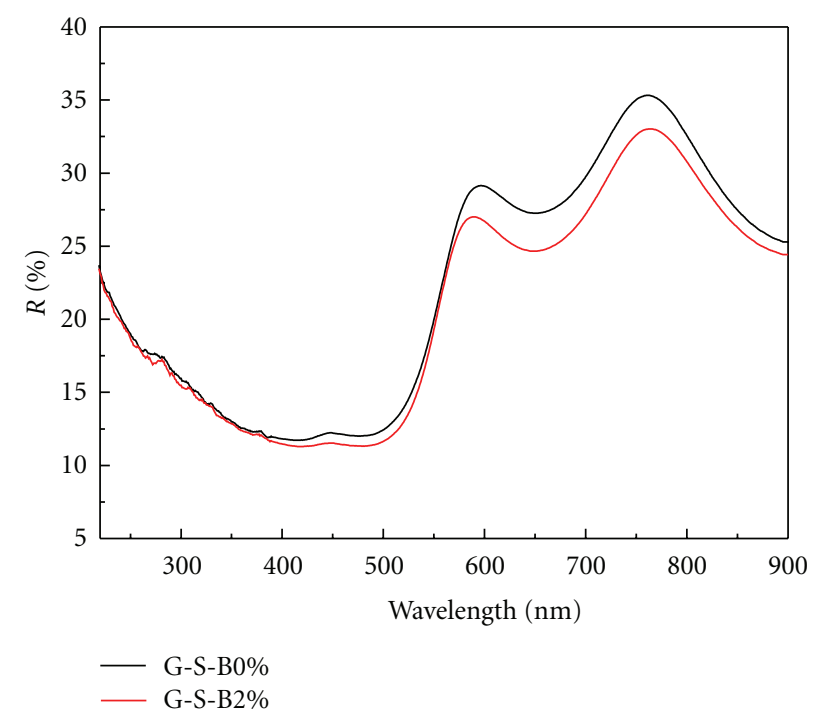

FIGURE 3: UV-visible light reflection spectrum of goethite and Bdoped goethite.

boron doping and heat treatment. Figure 1 shows the $\mathrm{X}$ ray diffraction patterns of goethite and B-doped goethite. Compared with G-S-B0\%, there is no significant new peak appearing in G-S-B2\%, but the intensity of some peaks become weaker or stronger. Maybe the content of boron is too small to make perceptible crystal change of goethite's structure by X-ray diffraction. But boron does make an influence in the crystal structure of goethite. Figure 2 shows the crystal form change of common hematite and hematite with $2 \%$ boron doping. It seems that $\mathrm{H}-\mathrm{S}-\mathrm{B} 0 \%$ and $\mathrm{H}-$ $\mathrm{S}-\mathrm{B} 2 \%$ have the same peaks. Perhaps the high calcination temperature destroyed the changes of doping.

3.2. UV-vis Diffuse Reflectance Spectra. Figure 3 illustrates the UV-vis light reflection spectrum of goethite and 


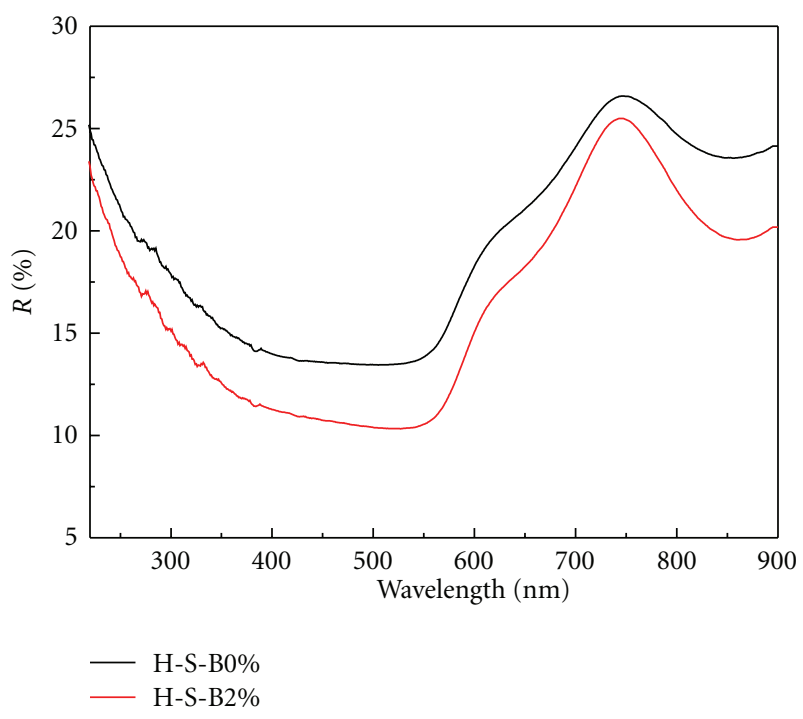

FIGURE 4: UV-visible light reflection spectrum of hematite and Bdoped hematite.

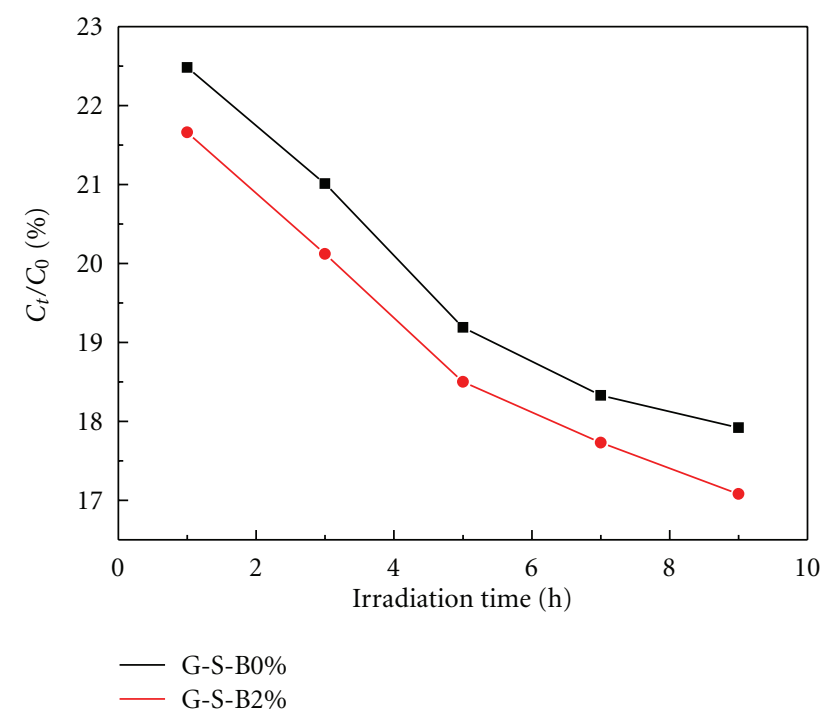

Figure 5: Atrazine degradation in present of goethite and B-doped goethite under visible light.

TABLE 1: The properties of different B-doped goethite and hematite.

\begin{tabular}{lcc}
\hline Samples & BET $\left(\mathrm{m}^{2} / \mathrm{g}\right)$ & Band-gap energy $(\mathrm{eV})$ \\
\hline G-S-B0\% & 60.24 & 2.06 \\
G-S-B2\% & 91.46 & 1.97 \\
H-S-B0\% & 56.26 & 1.69 \\
H-S-B2\% & 71.48 & 1.68 \\
\hline
\end{tabular}

boron-doped goethite. In the UV part, G-S-B0\% and G$\mathrm{S}-\mathrm{B} 2 \%$ show the same reflection rate, while in the visible part, G-S-B2\% shows stronger light absorption than G-S$\mathrm{B} 0 \%$. The UV-vis light reflection spectra of undoped and $2 \%$ boron-doped hematite were shown in Figure 4 . H-S$\mathrm{B} 2 \%$ shows stronger absorption than $\mathrm{H}-\mathrm{S}-\mathrm{B} 0 \%$ during the

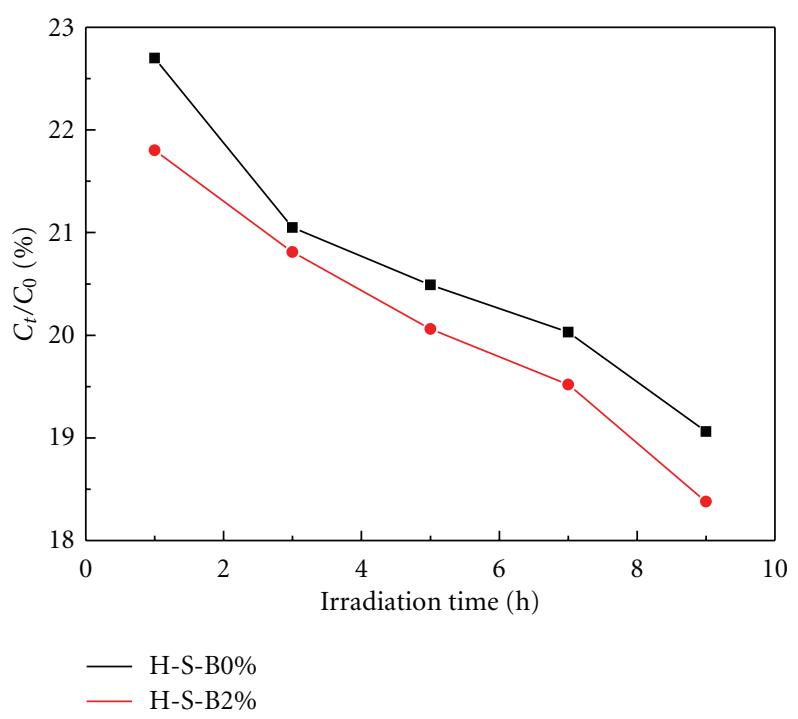

FIGURE 6: Atrazine degradation in present of hematite and B-doped hematite under visible light.

whole wavelength range. The band-gap energy of these four iron oxides were estimated by $\mathrm{Eg}=1240 / \lambda_{\text {onset }}[14]$ and presented in Table 1. It is inferred that boron doping may narrow the band-gap energy of iron oxides and improve their light absorption ability.

3.3. BET Surface Area. Table 1 lists the BET surface areas of four iron oxides. G-S-B2\% exhibits higher BET surface area than that of G-S-B0\% (34.13\%), and the BET surface area of $\mathrm{H}-\mathrm{S}-\mathrm{B} 2 \%$ is also larger than that of $\mathrm{H}-\mathrm{S}-\mathrm{B} 0 \%(21.29 \%)$. These results confirm that boron doping can efficiently inhibit the crystal size growth and increase the surface area of goethite and hematite.

3.4. Visible Light Photocatalysis of Atrazine. To examine the photocatalytic activity of B-doped iron oxides, atrazine was chosen as target contaminant. And the degradation rate of atrazine through the reaction time in present of these four iron oxides under visible light was displayed in Figures 5 and 6. The photocatalytic degradation of atrazine followed the first-order reaction kinetics under visible light according to $\ln C_{t}=\ln C_{0}-k t$, where $C_{0}$ stands for the initial concentration of atrazine and $C_{t}$ is the concentration of atrazine at $t$ time. All the numbers were collected in Table 2. The results clearly indicated that G-S-B2\% and $\mathrm{H}-\mathrm{S}-\mathrm{B} 2 \%$ revealed a substantially enhanced activity for degradation of atrazine, as compared to undoped G-S-B0\% and H-S$\mathrm{B} 0 \%$ under visible light irradiation. The first-order kinetics constants $(k)$ for atrazine degradation by G-S-B0\%, G$\mathrm{S}-\mathrm{B} 2 \%, \mathrm{H}-\mathrm{S}-\mathrm{B} 0 \%$, and $\mathrm{H}-\mathrm{S}-\mathrm{B} 2 \%$ were $0.0295 \mathrm{~h}^{-1}(\mathrm{R}=$ $0.9774), 0.0301 \mathrm{~h}^{-1}(R=0.9857), 0.0199 \mathrm{~h}^{-1}(R=0.9757)$, and $0.0202 \mathrm{~h}^{-1}(R=0.9932)$, respectively, and the half lives $\left(t_{1 / 2}\right)$ of atrazine degraded by them were $23.49 \mathrm{~h}, 23.02 \mathrm{~h}$, $34.82 \mathrm{~h}$, and $34.31 \mathrm{~h}$, respectively. It was confirmed that boron doping could show good optical activity and goethite 
TABLE 2: Degradation kinetic results of atrazine under visible light irradiation with different iron oxides.

\begin{tabular}{|c|c|c|c|c|}
\hline Experiments conditions & $\ln C_{t}=\ln C_{0}-k t$ & $R$ & $k\left(\mathrm{~h}^{-1}\right)$ & $t_{1 / 2}(\mathrm{~h})$ \\
\hline G-S-B0\% & $\ln C_{t}=0.8261-0.0295 t$ & 0.9774 & 0.0295 & 23.49 \\
\hline G-S-B2\% & $\ln C_{t}=0.7895-0.0301 t$ & 0.9857 & 0.0301 & 23.02 \\
\hline $\mathrm{H}-\mathrm{S}-\mathrm{B} 0 \%$ & $\ln C_{t}=0.8240-0.0199 t$ & 0.9757 & 0.0199 & 34.82 \\
\hline $\mathrm{H}-\mathrm{S}-\mathrm{B} 2 \%$ & $\ln C_{t}=0.7983-0.0202 t$ & 0.9932 & 0.0202 & 34.31 \\
\hline
\end{tabular}

had better catalytic activity than hematite under visible light irradiation.

\section{Conclusion}

The degradation of atrazine by using visible light-activated B-doped iron oxide as photocatalyst is demonstrated in this paper. Goethite, hematite, and B-doped goethite and hematite were successfully synthesized by a novel modified sol-gel method. Although there is no significant different in XRD results between pure iron oxide and B-doped iron oxide, however, the BET surface area and UV-vis spectra indicate that boron doping greatly influenced the properties of iron oxide. G-S-B2\% and H-S-B2\% exhibited enhanced visible light photocatalytic activity in degradation of atrazine compared with G-S-B0\% and H-S-B0\%, which maybe due to the stronger light adsorption and boron-doped goethite exhibited better photocatalytic activity than boron-doped hematite.

\section{Acknowledgments}

This work was supported jointly by the National Natural Science Foundation of China (40973056; 40371064) and Specialized Research Fund for the Doctoral Program of Higher Education (SRFDP) of the Ministry of Education of PRC (20100146110020).

\section{References}

[1] X. Z. Fan, B Lu, and A. J. Gong, "Dynamics of solar light photodegradation behavior of atrazine on soil surface," Journal of Hazardous Materials, vol. 117, no. 1, pp. 75-79, 2005.

[2] C. B. Zhang, L. Wang, G. Pan et al., "Degradation of atrazine photoinduced by $\mathrm{Fe}$ (III)-pyruvate complexes in the aqueous solution," Journal of Hazardous Materials, vol. 169, no. 1-3, pp. 772-779, 2009.

[3] J. C. Barreiro, M. D. Capelato, L. Martin-Neto, and H. C. B. Hansen, "Oxidative decomposition of atrazine by a Fentonlike reaction in a $\mathrm{H}_{2} \mathrm{O}_{2}$ /ferrihydrite system," Water Research, vol. 41, no. 1, pp. 55-62, 2007.

[4] N. Ta, J. Hong, T. F. Liu, and C. Sun, "Degradation of atrazine by microwave-assisted electrodeless discharge mercury lamp in aqueous solution," Journal of Hazardous Materials, vol. 138, no. 1, pp. 187-194, 2006.

[5] T. A. McMurray, P. S. M. Dunlop, and J. A. Byrne, "The photocatalytic degradation of atrazine on nanoparticulate $\mathrm{TiO}_{2}$ films," Journal of Photochemistry and Photobiology A, vol. 182, no. 1, pp. 43-51, 2006.
[6] L. P. Wackett, M. J. Sadowsky, B. Martinez, and N. Shapir, "Biodegradation of atrazine and related s-triazine compounds: from enzymes to field studies," Applied Microbiology and Biotechnology, vol. 58, no. 1, pp. 39-45, 2002.

[7] H. L. Chen, E. Bramanti, I. Longo, M. Onor, and C. Ferrari, "Oxidative decomposition of atrazine in water in the presence of hydrogen peroxide using an innovative microwave photochemical reactor," Journal of Hazardous Materials, vol. 186, no. 2-3, pp. 1808-1815, 2011.

[8] S. Parra, S. E. Stanca, I. Guasaquillo, and K. R. Thampi, "Photocatalytic degradation of atrazine using suspended and supported $\mathrm{TiO}_{2}$," Applied Catalysis B, vol. 51, no. 2, pp. 107116, 2004.

[9] K. Y. Jung, S. B. Park, and S. K. Ihm, "Local structure and photocatalytic activity of $\mathrm{B}_{2} \mathrm{O}_{3}-\mathrm{SiO}_{2} / \mathrm{TiO}_{2}$ ternary mixed oxides prepared by sol-gel method," Applied Catalysis B, vol. 51, no. 4, pp. 239-245, 2004.

[10] J. J. Xu, Y. H. Ao, M. D. Chen, and D. G. Fu, "Low-temperature preparation of boron-doped titania by hydrothermal method and its photocatalytic activity," Journal of Alloys and Compounds, vol. 484, no. 1-2, pp. 73-79, 2009.

[11] G. L. Liu, D. W. Zhu, W. B. Zhou et al., "Solid-phase photocatalytic degradation of polystyrene plastic with goethite modified by boron under UV-vis light irradiation," Applied Surface Science, vol. 256, no. 8, pp. 2546-2551, 2010.

[12] R. J. Atkinson, A. M. Posner, and J. P. Quirk, "Adsorption of potential-determining ions at the ferric oxide-aqueous electrolyte interface," The Journal of Physical Chemistry, vol. 71, no. 3, pp. 550-558, 1967.

[13] S. J. Liao, J. Wang, D. W. Zhu et al., "Structure and $\mathrm{Mn}^{2+}$ adsorption properties of boron-doped goethite," Applied Clay Science, vol. 38, no. 1-2, pp. 43-50, 2007.

[14] R. L. Qiu, L. Song, D. D. Zhang, Y. Q. Mo, E. Brewer, and X. F. Huang, "Characterization of conjugated polymer poly(fluorene-co-thiophene) and its application as photosensitizer of $\mathrm{TiO}_{2}$," International Journal of Photoenergy, vol. 2008, Article ID 164702, 5 pages, 2008. 


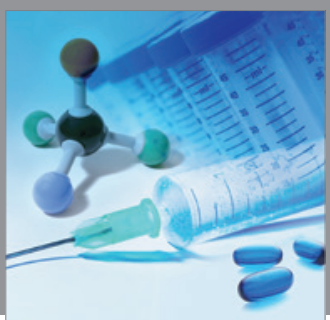

International Journal of

Medicinal Chemistry

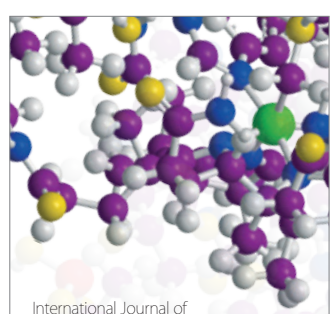

Carbohydrate Chemistry

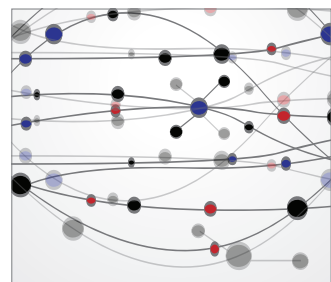

The Scientific World Journal
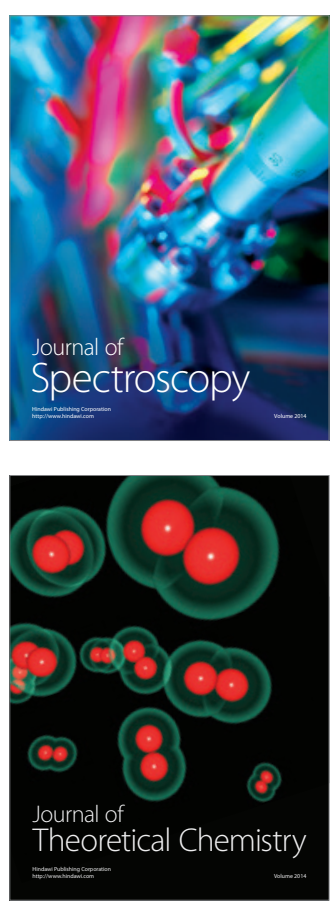
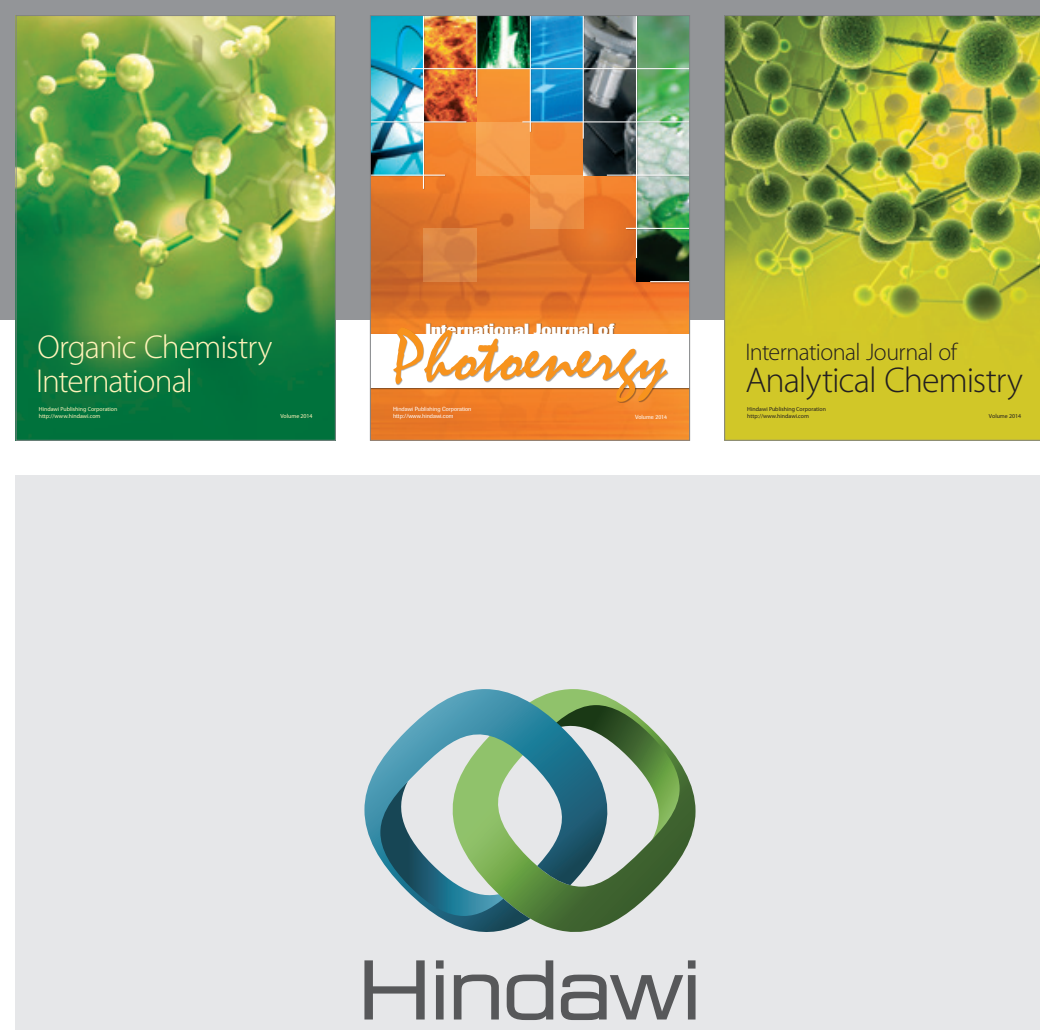

Submit your manuscripts at

http://www.hindawi.com
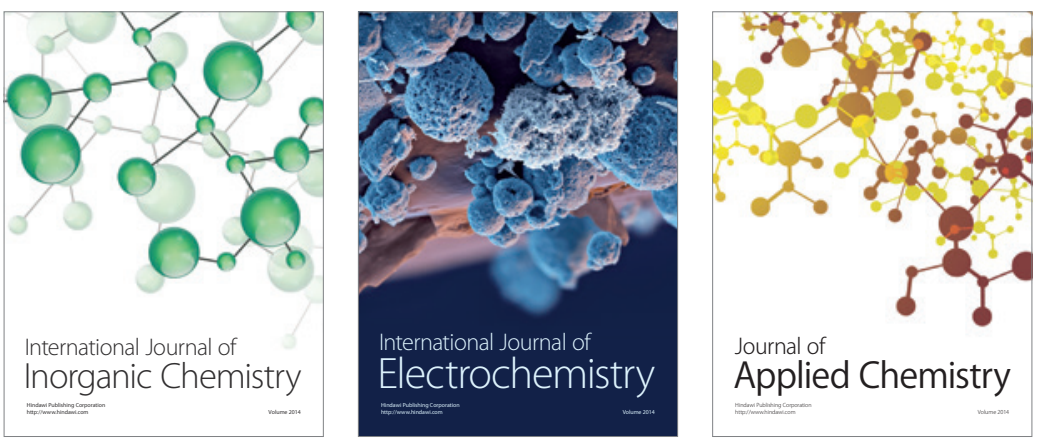

Journal of

Applied Chemistry
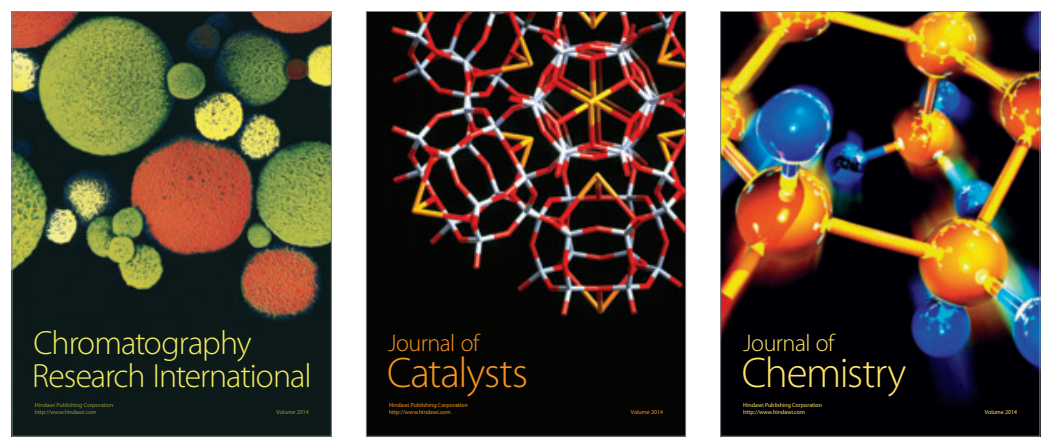
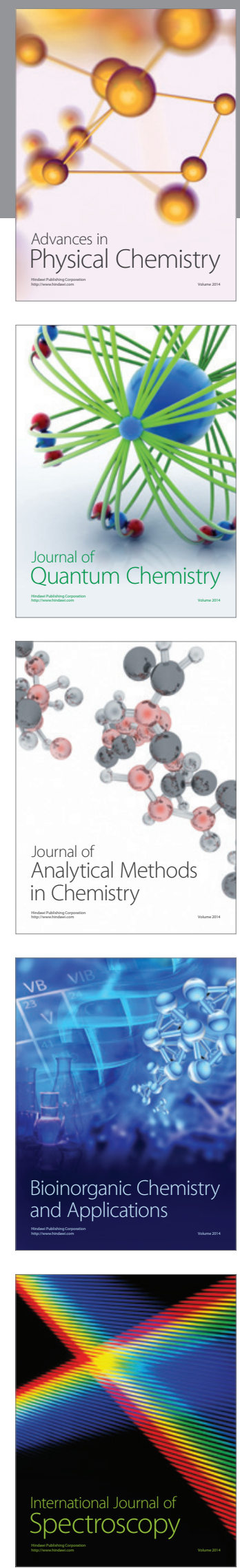